\title{
Determinants of Work in the Six-Minute Walk Test in School-Age Children
}

\author{
Determinantes do trabalho no Teste de Caminhada \\ de Seis Minutos em escolares
}

\section{Laura Alves Cabral ${ }^{[a]}\left(\mathbb{D}\right.$, Danielle Aparecida Gomes Pereira ${ }^{[b]}\left(\mathbb{D}\right.$, Cristino Carneiro Oliveira ${ }^{[a]}(\mathbb{D}$, Eliane Maria de Carvalho ${ }^{[c]}\left[\mathbb{D}\right.$, Marcelo Velloso ${ }^{[b]}[\mathbb{D} *$}

[a] Universidade Federal de Juiz de Fora (UFJF), Governador Valadares, MG, Brazil

[b] Universidade Federal de Minas Gerais (UFMG), Belo Horizonte, MG, Brazil

[c] Universidade Federal de Uberlândia (UFU), Uberlândia, MG, Brazil

\begin{abstract}
Introduction: The Six-Minute Walk Test (6MWT) is widely used to assess functional capacity in children. The measure of work during 6MWT can add important information to the 6MWT assessment in this population as it relates to walking efficiency. Objective: To verify the determinants of work during the Six-Minute Walk Test (6MWT ${ }_{\text {work }}$ ) in school-aged children. Method: This is a cross-sectional and exploratory study that included healthy children recruited from the public and private schools of the cities of Belo Horizonte and Uberlândia, Brazil. The inclusion criteria were: children aged 7 to 12 years without diagnosis of chronic cardiorespiratory disease, cognitive, behavioral disorder or physical function impairment (information obtained through self-report of those responsible for children). Exclusion criteria were children who refused to perform the 6MWT; who did not understand the 6MWT or who did not answer the test commands. Three hundred and nineteen school-aged children were included in the study. Correlation analyses and multiple linear regression analysis were used to identify the variables associated with the $6 \mathrm{MWT}_{\text {work }}$. Results: Age,
\end{abstract}

*LAC: PhD, e-mail: laura.cabral@ufjf.edu.br

DAGP: PhD, e-mail: danielleufmg@gmail.com

CCO: PhD, e-mail: cristino.oliveira@ufff.edu.br

EMC: PhD, e-mail: elianemc@faefi.ufu.br

MV: PhD, e-mail: marcello.vel@gmail.com 
height, nutritional status, physical activity and heart rate showed significant correlation with $6 \mathrm{MWT}_{\text {work }}(\mathrm{p}$ $<0.001)$ and explained $87 \%$ of its variation $(p=0.0001)$. Conclusion: Age, height, nutritional status and heart rate variation are determinants of $6 \mathrm{MWT}_{\text {work }}$ that is able to evaluate functional capacity of school-aged children.

Keywords: Children. Physical Fitness. Submaximal Exercise Testing. Walking.

\section{Resumo}

Introdução: $O$ teste de caminhada de seis minutos (TC6min) é amplamente utilizado para avaliar a capacidade funcional em crianças. A medida do trabalho durante o TC6 poderia adicionar informações importantes à avaliação do TC6 nessa população, no que se refere à eficiência da marcha. Objetivo: Verificar os determinantes do trabalho durante o Teste de Caminhada (TC6min) em crianças em idade escolar. Método: Trata-se de um estudo transversal e exploratório que incluiu crianças saudáveis recrutadas nas escolas públicas e privadas das cidades de Belo Horizonte e Uberlândia, Brasil. Os critérios de inclusão foram: crianças de 7 a 12 anos sem diagnóstico de doença cardiorrespiratória crônica, distúrbio cognitivo, comportamental ou comprometimento da função física (informações obtidas por auto-relato dos responsáveis pelas crianças). Os critérios de exclusão foram: crianças que se recusaram a realizar o TC6; que não entenderam o TC6 ou que não responderam aos comandos de teste. Trezentos e dezenove crianças em idade escolar foram incluídas no estudo. Análises de correlação e análise de regressão linear múltipla foram utilizadas para identificar as variáveis associadas ao trabalho com TC6. Resultados: Idade, altura, estado nutricional, atividade física e frequência cardíaca apresentaram correlação significativa com o trabalho durante o TC6min $(p<0,001)$ e explicaram $87 \%$ de sua variação $(p=0,0001)$. Conclusão: Idade, altura, estado nutricional e variação da frequência cardíaca são determinantes do trabalho no TC6, e portanto, devem ser considerados na avaliação da capacidade funcional de crianças em idade escolar.

Palavras-chave: Crianças. Aptidão Física. Teste de Exercício Submáximo. Caminhada.

\section{Introduction}

The Six-Minute Walk Test (6MWT) is widely used in the pediatric population to assess functional and exercise capacity in physiotherapy clinical practice and scientific research. The distance covered in this test $\left(6 \mathrm{MWT}_{\text {distance }}\right)$ is the endpoint used to measure the individual's performance [1-3]. The literature indicates that the work during the 6MWT (6MWT ${ }_{\text {work }}$ ) can add important value to test interpretation and physical capacity in the pediatric population [4-8]. The $6 \mathrm{MWT}_{\text {work }}$ is calculated by the product of the covered distance and body weight, it is described as a feasible and clinically useful measure for the assessment of functional and exercise capacities in healthy adults and children [4-10] and with chronic diseases. According with Chuang et al. [10], "converting walking distance to maximal exercise capacity is not easily done because of differences in the characteristics of the exercise and body weight factor confounding the walking performance".
The two main reasons to include an analysis of the $6 \mathrm{MWT}_{\text {work }}$ in the interpretation of the 6MWT are: 1) $6 \mathrm{MWT}_{\text {work }}$ correlated more with the maximal oxygen uptake and anaerobic threshold (determined from the cardiopulmonary exercise test), with the change distance in Borg score and pulse oxygen saturation $\left(\mathrm{SpO}_{2}\right)$ in the 6MWT and self-assessed every-day activities in patients with Chronic Obstructive Pulmonary Disease; and 2) 6MWT ${ }_{\text {work }}$ was better correlated with diffusing capacity for carbono monoxide and vital capacity in these patients [11-13].

In the pediatric population, $6 \mathrm{MWT}_{\text {work }}$ was first investigated by Cunha et al. [4] in children and adolescents with cystic fibrosis and another study with healthy children. The authors evidenced that the $6 \mathrm{MWT}_{\text {work }}$ measure showed a strong correlation with height and moderate correlation with the maximum expiratory pressure, systolic blood pressure and diastolic blood 
pressure, concluding that this measure may be an additional parameter to determine the physical capacity of children with cystic fibrosis. Other studies have been carried out with children to explore the $6 \mathrm{MWT}_{\text {work }}$, noting that this measure adds important information in the interpretation of the 6MWT results in this population, especially in the evaluation of exercise capacity in children with other diseases $[5,7,8]$.

Age, sex, weight, height, BMC and difference between HR post $6 \mathrm{MWT}$ and resting HR $\left(\Delta_{-} \mathrm{HR}\right)$ are factors associated with the $6 \mathrm{MWT}$ and predictors of $6 \mathrm{MW}_{\text {distance }}$ in healthy children [14-22], being BMC and $\Delta_{-}$HR poorly explored in scientific research. Considering the high clinical applicability of 6MWT $[1,3,23]$ and the relation of 6MWT ${ }_{\text {work }}$ to functional and exercise capacity in children $[4,5,7,8]$, it is also relevant to investigate which factors influence this measure. Thus, the objectives of the present study were to verify the determinants of the $6 \mathrm{MWT}_{\text {work }}$ in school-aged children.

\section{Method}

This is a cross-sectional and exploratory study that included healthy children recruited from the public and private schools of the cities of Belo Horizonte and Uberlândia, Brazil. The present study was part of a large multicenter study, that aimed to establish the $6 \mathrm{MWT}_{\text {distance }}$ reference values for the Brazilian healthy children [2]. The data were collected at the University from March to November 2014. All participants and their parents or legal guardians provided written consent, based upon previous approval from the Research Ethical Committee of the Universidade Federal de Minas Gerais (CAAE 08827713.1.2011.5149).

The inclusion criteria were: children aged 7 to 12 years without diagnosis of chronic cardiorespiratory disease, cognitive, behavioral disorder or physical function impairment (information obtained through selfreport of those responsible for children). Exclusion criteria were children who refused to perform the 6MWT; who did not understand the 6MWT or who did not answer the test commands.

Before test procedures, demographic and anthropometric data were obtained. A precise digital weighing scale with an accuracy up to $180 \mathrm{~kg}$ (Yeshm Eletronic Personal Scale-China/) was used to measure body mass. Nutritional status was evaluated and classified, according to the World Health Organization (WHO) reference values [24]. Information regarding the frequency of physical activity practice was obtained from the parents' reports.

The 6MWT was administered by experienced researchers and was performed on a 30-meter corridor, following the American Thoracic Society (ATS) guidelines [25]. Before the test, the children remained seated on a chair near the start line for at least $10 \mathrm{~min}$, when heart rate (HR) and peripheral oxygen saturation $\left(\mathrm{SpO}_{2}\right)$ data were recorded. The children received the following command: walk as fast as possible, without running over six minutes and the total covered distance for six minutes was registered for analysis. If there was any interruption, the time continued to be recorded and standardized encouragement was provided every two minutes [25]. $\mathrm{HR}$ and $\mathrm{SpO}_{2}$, were measured using a pulse oximeter (Tuffsat User \& Service) and were continuously monitored during the test. At the end, the children were asked to sit on a chair and $\mathrm{HR}, \mathrm{SpO}_{2}$, perception of effort (Modified Borg Scale) [26] measures were collected immediately after the test and at after one and two minutes of recovery. If the children complained of any discomfort and expressed the desire to stop the test, the protocol was discontinued and their were excluded from the study.

The $6 \mathrm{MWT}_{\text {work }}$ was calculated, using the following formula: $6 \mathrm{MWT}$ distance $(\mathrm{m})$ * body weight $\left(\mathrm{kg} \cdot \mathrm{m} / \mathrm{s}^{2}\right)$, considering the acceleration of gravity of $9.8 \mathrm{~m} / \mathrm{s}^{2}$, and reported in Joules (J). This calculation was based on study performed by Chuang etal. [10] using the assumptions of the original study on the measure of work postulated by Cavagna et al. [12] Therefore, the work of walking on the horizontal equals the product of distance and weight.

The sample size of the present study was based upon the calculation for the multicenter study. For this calculation, 11 sub-populations were considered, covering all regions of Brazil, according to the Brazilian Demographic Data in 2010 [2]. Thus, since this study involved two centers located in Minas Gerais state, the sample size was defined as 158 children per center. First, an invitation letter was addressed to the principals of the public and private schools. After acceptance, a meeting was held with the children's parents to present the study protocol. Participated in the study the children whose parents allowed participation through written informed consent and who met the study inclusion criteria. The calculation of the sample size for the regression analysis was performed considering the calculation formula $\mathrm{n}=$ $10(\mathrm{k}+1)$, where $\mathrm{n}$ is the required sample number and $\mathrm{k}$ is the number of explanatory variables [27]. 
Descriptive statistics (measures of central tendency and dispersion), frequencies, and tests of normality of distribution (Shapiro-Wilk) were carried-out for all variables. To identify the variables correlated with $6 \mathrm{MWT}_{\text {work' }}$, we used the Pearson Correlation Test for the height and $\triangle \mathrm{HR}$ variables in the 6MWT and the Spearman Correlation Test for age, sex, nutritional status and physical activity. The children in the present study were classified into six subgroups according to age (Group 1 - 7 years old; Group 2 - 8 years old; Group 3 - 9 years old; Group 4 - 10 years old; Group 5 - 11 years old; Group 6 - 12 years old); this variable was operationalized as a categorical data in the correlation analysis. To verify the existence of association of the $6 \mathrm{MWT}_{\text {work }}$ dependent variable with the significant explanatory variables in the correlation tests, multiple linear regression analysis was performed - stepwise backward method. All analyses were carried-out with the Statistical Package for the Social Sciences (version 17.0). The significance level established was of $5 \%$.

\section{Results}

Three hundred and twenty-four children were evaluated. Data from five were excluded, for the following reasons: could not understand the test procedures (one), difficulty in assessing the perceptions of effort (two), and lack of information on physical activity practice (one) and $\mathrm{SpO}_{2}$ (one). The final sample consisted of 172 females and 147 males. Table 1 shows the characteristics of the participants in relation to age, sex, nutritional status, physical activity, body weight and height. A total of 138 children (43.3\%) were on regular physical activity, of which 85 were female (61\%). The mean weekly exercise frequency was $2.45( \pm$ 1.08) times per week. The variables assessed in the 6MWT are shown in Table 2.

The correlation analysis showed that age $(r=0.63)$, nutritional status $(\mathrm{r}=0.40)$, physical activity practice $(\mathrm{r}$ $=0.21), \Delta \mathrm{HR}(\mathrm{r}=0.24)$ and height $(\mathrm{r}=0.68)$ were significantly and positively related to $6 \mathrm{MWT}_{\text {work }}(\mathrm{p}<0.001)$ (Figure 1); sex was not correlated ( $\mathrm{p}=0.72$ ). Multiple linear regression analysis showed that age, height, nutritional status and $\Delta \mathrm{HR}$ explained $87 \%$ of the $6 \mathrm{MWT}_{\text {work }}$ variation in the children evaluated $(p=0.0001)$ (Table 3 and Figure 1). Physical activity did not contribute significantly to this model $(\mathrm{p}>0.05)$.
Table 1 - Characteristics of participants

\begin{tabular}{|c|c|}
\hline Variables & $(n=319)$ \\
\hline \multicolumn{2}{|l|}{ Age, n (\%) } \\
\hline 7 years & $53(16.6)$ \\
\hline 8 years & $54(16.9)$ \\
\hline 9 years & $57(17.9)$ \\
\hline 10 years & $48(15)$ \\
\hline 11 years & $54(16.9)$ \\
\hline 12 years & $53(16.6)$ \\
\hline \multicolumn{2}{|l|}{ Sex, n (\%) } \\
\hline Girls & $172(53.9)$ \\
\hline Boys & $147(46.1)$ \\
\hline \multicolumn{2}{|l|}{ Nutritional Status, n (\%) } \\
\hline Low weight & $9(2.8)$ \\
\hline Eutrophic & $200(62.7)$ \\
\hline Overweight & $62(19.4)$ \\
\hline Obese & $48(15)$ \\
\hline \multicolumn{2}{|l|}{ Physical Activity Practice, n (\%) } \\
\hline Practitioners & $138(43.3)$ \\
\hline Not practitioners & $181(56.7)$ \\
\hline Weight $(\mathrm{kg})$, average (SD) & $36.89(10.97)$ \\
\hline Height $(m)$, average (SD) & $1.41(0.33)$ \\
\hline
\end{tabular}

Note: SD = standard deviation

Table 2 - Variables evaluated in the Six-Minute Walk Test

\begin{tabular}{cc}
\hline Variables $(\mathbf{n}=319)$ & Average (SD) \\
\hline HRrest $(\mathrm{bpm})$ & $91.15(14.68)$ \\
HRend_6MWT (bpm) & $100.52(18.92)$ \\
AHR_6MWT (bpm) & $9.71(17.37)$ \\
HRR1_6MWT (bpm) & $94.74(16.04)$ \\
HRR2_6MWT (bpm) & $93.12(16.36)$ \\
Sp0_rest (\%) & $95.78(4.14)$ \\
Sp0_end_6MWT (\%) & $95.16(3.70)$ \\
Borg end_6MWT & $1.40(1.67)$ \\
6MWT & $481.11(89.33)$ \\
6istance & $(m)$ \\
\hline
\end{tabular}

Note: SD = standard deviation; 6MWT: Six-Minute Walk Test; HR $=$ Heart Rate; $\Delta \mathrm{HR}$ 6MWT $=\mathrm{HR}$ post 6MWT minus resting HR; HRR1 6MWT: Heart Rate Recovery at one minute after the Six-Minute Walk Test; HRR2_6MWT: Heart Rate Recovery at one minute after the Six-Minute Walk Test; $\mathrm{SpO}_{2}=$ Peripheral Oxygen Saturation; $6 \mathrm{MWT}_{\text {distance }}=$ Distance traveled in the Six-Minute Walk Test; $6 \mathrm{MWT}_{\text {work }}$ $=$ Work on the Six Minute Walk Test. 

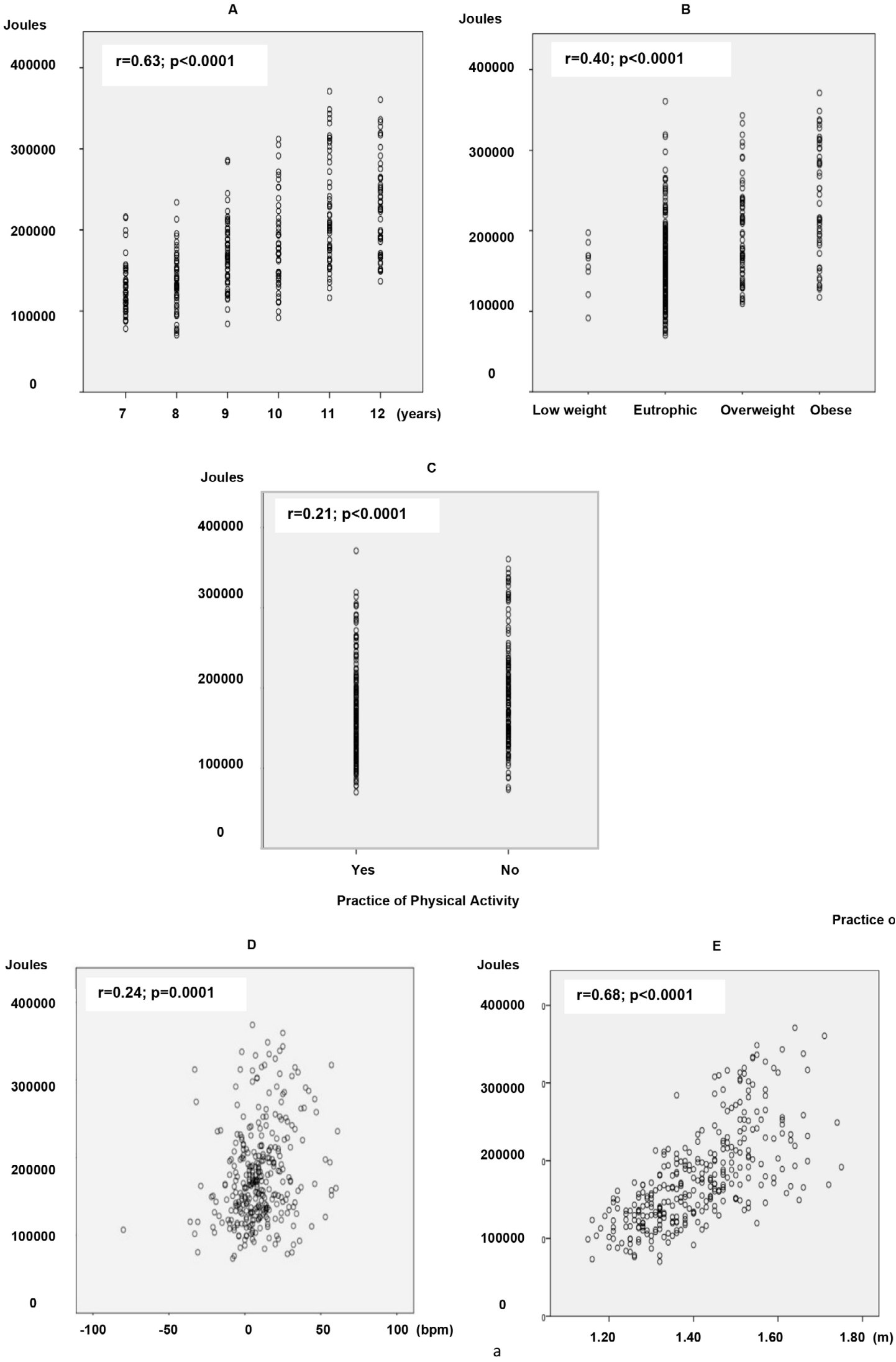

Note: A: $6 \mathrm{MWT}_{\text {work }}$ (Joules) versus age (years); B: $6 \mathrm{MWT}_{\text {work }}$ (Joules) versus Nutritional Status; C: 6MWT work $_{\text {(Joules) versus Practice of }}$

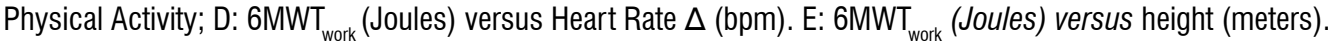


Table 3 - Multiple linear regression of the determinants of work on the Six-Minute Walk Test (6MWT work )

\begin{tabular}{lccc}
\hline \multicolumn{1}{c}{ Explanatory } & $\mathbf{R}^{2}$ & $\beta$ & p-value \\
variables & & & \\
Constant & 0.87 & 40653.52 & $<0.0001$ \\
Age & & 446.22 & 0.03 \\
Height & & 35389.04 & 0.0001 \\
Nutritional & & 3348.21 & 0.0001 \\
Status $^{\mathrm{a}}$ & & 97.55 & 0.0001 \\
$\Delta$ HR_6MWT & & &
\end{tabular}

Note: $\mathrm{R}^{2}=$ Determination coefficient. ${ }^{\mathrm{a}}=1$ Low weight; 2 Eutrophic; 3 Overweight; 4 Obese. $\triangle \mathrm{HR}$ 6MWT $=$ Six-minute walk test final heart rate - resting heart rate.

\section{Discussion}

The main finding of this study is: age, height, nutritional status and $\Delta \mathrm{HR}$ are important determinants of $6 \mathrm{MWT}_{\text {work }}$ in school-age children. Studies about $6 \mathrm{MWT}_{\text {distance }}$ in school-aged healthy children show that age, weight, height and $\Delta$ HR can explain around 36,6 to $60 \%$ of the variation of the distance covered by these individuals [15,17 - 20]. In the present study, age, height, nutritional status and $\Delta \mathrm{HR}$ explained $87 \%$ of the variation of the work produced by the children in 6MWT. This finding is similar to the study by Silva et al. [5] who also used the work as an outcome measure of the 6MWT. These authors studied children and adolescents after lung transplantation and found that $6 \mathrm{MWT}_{\text {work }}$ showed a significant correlation with age, anthropometric parameters (weight, height, BMI) and pulmonary function (forced vital capacity, peak expiratory flow rate and volume expiratory). These authors demonstrated that age, expiratory volume and PEF explained $80 \%$ of the $6 \mathrm{MWT}_{\text {work }}$ variation, which means that this measure could add important value in determining the functional capacity of these individuals and seems to be a more robust measure than $6 \mathrm{MWT}_{\text {distance }}$ alone.

Age and height were the variables that presented the highest correlation with $6 \mathrm{MWT}_{\text {work }}$ among the others evaluated. Cunha et al. [4], Silva et al. [5], Hassan et al. [7] and Lesser et al. [8] also found similar results in children with chronic diseases and healthy conditions. However, Silva et al. [5] and Lesser et al. [8] found a significant correlation between age, body weight, height and $6 \mathrm{MWT}_{\text {work' }}$ with body weight and height, being the variables that presented the highest correlation with this measure. In the studies by Cunha et al.
[4] and Hassan et al. [7], the highest correlation was found between height and $6 \mathrm{MWT}_{\text {work }}$ in children with cystic fibrosis, hemophilia, juvenile idiopathic arthritis, spina bifida and healthy volunteers. It is known that age is a variable that directly influences $6 \mathrm{MWT}_{\text {distance' }}$ older children have a better performance in the 6MWT $[15,18$ - 20]. Therefore, these children also tend to have a higher capacity to generate $6 \mathrm{MWT}_{\text {work }}[5,28]$. This capacity is associated with the maturity of body systems during development, especially the musculoskeletal system, which leads to the possibility of greater mechanical efficiency in walking due to the greater capacity of storage, transfer and recovery of potential elastic energy [11,29].

Height is one of the most widely used anthropometric parameters in pediatric clinical practice and is considered to be a more robust measure than age itself in relation to the 6MWT performance, since children are constantly in the process of growth and development. Children of the same age and different heights tend to present different performances in the 6MWT $[1,5,19]$. Higher individuals have a greater lever arm due to the longer distance of the BMC relative to the ground, which generates greater anterior displacement of the body, and therefore, greater work and energy production during walking. This favors greater storage of elastic potential energy through the mechanical energy produced by the body to displace the BMC in space, as well as the transfer of this energy to the movement of the upper and lower limb during walking [11,29]. Therefore, depending on the studied population, in addition to age, height should also be considered in the assessment of functional capacity through $6 \mathrm{MWT}_{\text {work }}$.

The nutritional status evaluated through the BMI showed a significant correlation with the $6 \mathrm{MWT}_{\text {work }}$. This finding can be explained by the small variation found among the different classifications of nutritional status of the children evaluated. Conversely, Lesser et al. and Silva et al. demonstrated that BMI had a moderate correlation with $6 \mathrm{MWT}_{\text {work }}$ in healthy and cystic fibrosis children [8] and in children after lung transplantation [5]. In the study of Hassan et al. [7] similar findings were observed in children with chronic conditions and healthy conditions.

Nutritional status analysis is relevant in the functional evaluation of children, since mass gain is associated with an increase in overweight and obesity. This does not necessarily imply higher $6 \mathrm{MWT}_{\text {work }}$ production, since these conditions lead to worse 6MWT performance for the age group (lower $6 \mathrm{MWT}_{\text {distance }}$ ) in 
addition to generating metabolic overload to the individual $[1,30]$. Compared to adults, the height and weight directly influence the work produced during walking, considering the body's necessary displacement in the environment. This is particularly applicable to children, who present a higher energy cost per kilogram of body weight per meter of distance traveled $[13,29,30]$.

The $\triangle \mathrm{HR}$ in the 6MWT is a variable influenced by age, sex, BMI and level of physical activity $[8,18,19,22]$. In the present study, there was a positive and weak correlation of this variable with $6 \mathrm{MWT}_{\text {work }^{\prime}}$ which can be explained by the value and variability observed in the $\Delta H R$ of the children evaluated. Despite this result, it could be inferred that children whose $\Delta \mathrm{HR}$ was higher tended to produce higher $6 \mathrm{MWT}_{\text {work }}$. Studies show that HR during the 6MWT in healthy school-aged children ranges [18] from 23 to $80 \%[14,15,17,19,20-22]$ and that this measure is directly associated with the $6 \mathrm{MWT}_{\text {distance }}$ Therefore, this variability of the chronotropic response in children during the 6MWT is expected and is an important hemodynamic parameter that should be considered in the evaluation of the functional capacity of these individuals.

Cunha et al. [4] and Lesser et al. [8] found no relationship between 6MWT $\mathrm{Mork}_{\text {w }}$ and hemodynamic and cardiovascular responses in healthy children. However, this relationship was observed in children with chronic diseases. The study by Cunha etal. [4] showed that there is a moderate correlation between blood pressure and $6 \mathrm{MWT}_{\text {work }}$ in children with cystic fibrosis. Lesser et al. [8] found a moderate correlation between HR in maximal oxygen consumption and $6 \mathrm{MWT}_{\text {work }}$ and strong oxygen pulse and $6 \mathrm{MWT}_{\text {work }}$ in healthy children and with cystic fibrosis assessed by the 6MWT and in the maximum exercise test. The 6MWT ${ }_{\text {work }}$ represents exercise capacity in sick children, becoming a relevant measure for clinical practice, since these children are not always able to perform maximal exercise tests to obtain the maximal oxygen consumption [8].

Physical activity showed a positive but weak correlation with $6 \mathrm{MWT}_{\text {work }}$ and did not contribute to the regression model. This result can be explained by the fact that this variable is influenced by other factors, such as the type of physical activity, the child's life style and the time spent with other activities of daily living, in relation to the child's performance in 6MWT $[14,15,17-22]$. However, Saad et al. [20] and Ulrich et al. [22] evaluated the relationship of physical activity with the 6MWT performance in healthy school-aged children and the results showed that the frequency of

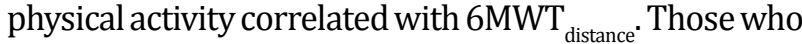
practice physical activity and who present with higher frequency in practice are more likely to have $6 \mathrm{MWT}_{\text {distance }}$ longer [20,22].

Lesser et al. [8] also showed that children with higher physical activity are able to sustain the effort during the 6MWT when assessed by means of the maximum treadmill stress test, which takes into account the interference of motivation for performance in the test [5]. Thus, regarding the analysis of the relationship between physical activity and 6MWT ${ }_{\text {work }}$ in the present study, it suggests that physical activity alone does not determine the ability to generate $6 \mathrm{MWT}_{\text {work }}$ in children. However, the type and frequency of the activities may influence this ability. This points out to the need for future studies that investigate the relationship between physical activity practice parameters and $6 \mathrm{MWT}_{\text {work }}$.

The present study has some limitations. First, other kinematic variables, such as stride length and cadence, which is known to influence walking speed, were not evaluated. Second, internal and external forces involved in walking, which would provide the analysis of the total energy efficiency, were not calculated.

It is worth to highlight that the inclusion of the $6 \mathrm{MWT}_{\text {work }}$ for the assessment of functional capacity is this measure easily obtained and its determinants brings information relevant for the area of pediatric physiotherapy in different conditions, such as cardiorespiratory and neuromusculoskeletal diseases. These individuals, in general, have poor mechanical efficiency, higher energy expenditure and metabolic costs during activities of daily living, including walking.

\section{Conclusion}

Age, height, nutritional status and heart rate variation are determinants of $6 \mathrm{MWT}_{\text {work }}$ that is able to evaluate functional capacity of school-aged children.

\section{References}

1. Bartels B, Groot JF, Terwee CB. The Six-Minute Walk Test in Chronic Pediatric Conditions: A Systematic Review of Measurement Properties. Phys Ther. 2013;93(4):529-41. 
2. Cacau LAP, Carvalho VO, Pin AS, Daniel CRA, Ykeda DS, Carvalho EM, et al. Reference Values for the 6-min Walk Distance in Healthy Children Age 7 to 12 Years in Brazil: Main Results of the TC6minBrasil Multi-Center Study. Respir Care. 2018;63(3):339-46.

3. Mylius CF, PaapD, Takken T. Reference value for the6-minute walk test in children and adolescents: a systematic review. Expert Rev Respir Med. 2016;10(12):1335-52.

4. Cunha MT, Rozov T, Oliveira RC, Jardim JR. Six-minute walk test in children and adolescents with cystic fibrosis. Pediatr Pulmonol. 2006;41(7):618-22.

5. Silva RM, Carvalho WB, Johnston C, Castro MB, Ferreira IM, Patti CL, et al. Functional capacity after pediatric liver transplantation: A pilot study. Pediatr Transplant. 2014;18(6):586-93.

6. Ferreira MS, Mendes RT, Marson FAL, Zambon MP, Paschoal IA, Toro AADC, et al. The relationship between physical functional capacity and lung function in obese children and adolescents. BMC Pulm Med. 2014;14:199.

7. Hassan J, van der Net J, Helders PJM, Prakken BJ, Takken T. Six-minute walk test in children with chronic conditions. Br J Sports Med. 2010;44(4):270-4.

8. Lesser DJ, Fleming MM, Maher CA, Kim SB, Woo MS, Keens TG. Does the 6-min walk test correlate with the exercise stress test in children? Pediatr Pulmonol. 2010;45(2):135-40.

9. Carter R, Holiday DB, Nwasuruba C, Stocks J, Grothues C, Tiep B. 6-minute walk work for assessment of functional capacity in patients with COPD. Chest. 2003;123(5):1408-15.

10. Chuang ML, Lin IF, Wasserman K. The body weightwalking distance product as related to lung function, anaerobic threshold and peak VO2 in COPD patients. Respir Med. 2001;95(7):618-26.

11. Cavagna GA, Franzetti P, Fuchimoto T. The mechanics of walking in children. J Physiol. 1983;343:323-39.

12. Cavagana GA, Saibene FP, Margaria R. External work in walking. J Appl Physiol. 1963;18(1):1-9.

13. Schepens B. Mechanical work and muscular efficiency in walking children. J Exp Biol. 2004;207:587-96.

14. D’Silva C, Vaishali K, Venkatesan P. Six-minute walk test-normal values of school children aged 7-12 y in India: A cross-sectional study. Indian J Pediatr. 2012;79(5): 597-601.
15. Stockman JA. Six-Minute Walk Test in Children and Adolescents. Yearb Pediatr. 2009;2009:466-9.

16. Klepper SE, Muir N. Reference values on the 6-minute walk test for children living in the United States. Pediatr Phys Ther. 2011;23(1):32-40.

17. Lammers AE, Hislop AA, Flynn Y, Haworth SG. The 6-minute walk test: Normal values for children of 4-11 years of age. Arch Dis Child. 2008;93(6):464-8.

18. Li AM, Yin J, Au JT, So HK, Tsang T, Wong E, et al. Standard reference for the six-minute-walk test in healthy children aged 7 to 16 years. Am J Respir Crit Care Med. 2007;176(2):174-80.

19. Priesnitz CV, Rodrigues GH, Stumpf CS, Viapiana G, Cabral CP, Stein RT, et al. Reference values for the 6-min walk test in healthy children aged 6-12 years. Pediatr Pulmonol. 2009;44(12):1174-9.

20. Saad H Ben, Prefaut C, Missaoui R, Mohamed IH, Tabka Z, Hayot M. Reference equation for 6-min walk distance in healthy North African children 6-16 years old. Pediatr Pulmonol. 2009;44(4):316-24.

21. Tonklang N, Roymanee S, Sopontammarak S. Developing standard reference data for thai children from a sixminute walk test. J Med Assoc Thail. 2011;94(4):470-5.

22. Ulrich S, Hildenbrand FF, Treder U, Fischler M, Keusch S, Speich R, et al. Reference values for the 6-minute walk test in healthy children and adolescents in Switzerland. BMC Pulm Med. 2013;513:49.

23. Cacau LP, Santana-Filho VJ, Maynard LG, Gomes Neto M, Fernandes M, Carvalho VO. Reference Values for the Six-Minute Walk Test in Healthy Children and Adolescents: a Systematic Review. Braz J Cardiovasc Surg. 2016;31(5):381-8.

24. Members of the WHO Multicentre Growth Reference Study Group. WHO Child Growth Standards. World Heal Organ. 2007 [cited 2019 Apr 22]. Available from: https://www.who.int/childgrowth/en/.

25. American Thoracic Society. Guidelines for the Six-minute walk test. Am J Respir Crit Care Med. 2002;166:111-7.

26. Borg GV. Psychophysical bases of perceived exertion. Med Sci Sports Exercise. 1982;14(5):377-81.

27. Brooks GP, Barcikowski RS. The PEAR Method for sample sizes in multiple linear regression. Mult Linear Regress Viewpoints. 2012;38(2):1-16. 
28. Saibene F, Minetti AE. Biomechanical and physiological aspects of legged locomotion in humans. Eur J Appl Physiol. 2003;88(4-5):297-316

29. van de Walle P, Desloovere K, Truijen S, Gosselink R, Aerts $P$, Hallemans A. Age-related changes in mechanical and metabolic energy during typical gait. Gait Posture. 2010;31(4):495-501.
30. Ebbeling CJ, Hamill J, Freedson PS, Rowland TW. An Examination of Efficiency during Walking in Children and Adults. Pediatr Exerc Sci. 2016;4:36-49.

Received: 02/06/2020

Recebido: 06/02/2020

Approved: 07/06/2020

Aprovado: 06/07/2020 